\title{
Photochemical aging of volatile organic compounds associated with oil and natural gas extraction in the Uintah Basin, UT, during a wintertime ozone formation event
}

\author{
A. R. Koss ${ }^{1,2}$, J. de Gouw ${ }^{1,2}$, C. Warneke ${ }^{1,2}$, J. B. Gilman ${ }^{1,2}$, B. M. Lerner $^{1,2}$, M. Graus ${ }^{1,2,{ }^{*}}$, B. Yuan ${ }^{1,2}$, \\ P. Edwards ${ }^{1,2, * *}$, S. S. Brown ${ }^{2}$, R. Wild ${ }^{1,2}$, J. M. Roberts ${ }^{2}$, T. S. Bates ${ }^{3,4}$, and P. K. Quinn ${ }^{4}$ \\ ${ }^{1}$ Cooperative Institute for Research in Environmental Sciences, Univ. of Colorado, Boulder, CO, USA \\ ${ }^{2}$ NOAA Earth System Research Laboratory, Chemical Sciences Division, Boulder, CO, USA \\ ${ }^{3}$ Joint Institute for the Study of the Atmosphere and Ocean, University of Washington, Seattle, WA, USA \\ ${ }^{4}$ NOAA/Pacific Marine Environmental Laboratory, Seattle, WA, USA \\ *now at: Institute of Meteorology and Geophysics, Innsbruck University, Innsbruck, Austria \\ ** now at: Department of Chemistry, University of York, York, YO10 5DD, UK
}

Correspondence to: A. R. Koss (abigail.koss@noaa.gov)

Received: 5 February 2015 - Published in Atmos. Chem. Phys. Discuss.: 5 March 2015

Revised: 4 May 2015 - Accepted: 5 May 2015 - Published: 26 May 2015

\begin{abstract}
High concentrations of volatile organic compounds (VOCs) associated with oil and natural gas extraction were measured during a strong temperature inversion in the winter of 2013 at a rural site in the Uintah Basin, Utah. During this period, photochemistry enhanced by the stagnant meteorological conditions and concentrated VOCs led to high ozone mixing ratios (150 ppbv). A simple analysis of aromatic VOCs measured by proton-transfer-reaction mass-spectrometry (PTR-MS) is used to estimate (1) VOC emission ratios (the ratio of two VOCs at the time of emission) relative to benzene, (2) aromatic VOC emission rates, and (3) ambient $\mathrm{OH}$ radical concentrations. These quantities are determined from a best fit to VOC: benzene ratios as a function of time. The main findings are that (1) emission ratios are consistent with contributions from both oil and gas producing wells; (2) the emission rate of methane $\left(27-57 \times 10^{3} \mathrm{~kg}\right.$ methane $\left.\mathrm{h}^{-1}\right)$, extrapolated from the emission rate of benzene $\left(4.1 \pm 0.4 \times 10^{5}\right.$ molecules $\left.\mathrm{cm}^{-3} \mathrm{~s}^{-1}\right)$, agrees with an independent estimate of methane emissions from aircraft measurements in 2012; and (3) calculated daily $\mathrm{OH}$ concentrations are low, peaking at $1 \times 10^{6}$ molecules $\mathrm{cm}^{-3}$, and are consistent with Master Chemical Mechanism (MCM) modeling. The analysis is extended to photochemical production of oxygenated VOCs measured by PTR-MS and is able to explain daytime variability of these species. It is not able to completely reproduce
\end{abstract}

nighttime behavior, possibly due to surface deposition. Using results from this analysis, the carbon mass of secondary compounds expected to have formed by the sixth day of the stagnation event was calculated, then compared to the measured mass of primary and secondary compounds. Only $17 \%$ of the expected secondary carbon mass is accounted for by gas phase, aerosol, and snow organic carbon measurements. The disparity is likely due to substantial amounts of unquantified oxygenated products.

\section{Introduction}

Natural gas, crude oil, and natural gas liquids are major fuel sources - accounting for $54 \%$ of 2013 US domestic energy production - and extraction of these resources has been rising substantially since the mid 2000s (US Energy Information Administration, 2014). This activity is associated with a range of possible environmental issues. Emissions due to extraction can increase atmospheric concentrations of methane, a greenhouse gas (Miller et al., 2013; Brandt et al., 2014); directly impact local air quality through release of air toxics (Moore et al., 2014; Adgate et al., 2014; Li et al., 2014); and contribute to photochemical ozone formation (Schnell et al., 2009; Edwards et al., 2014; Carter and Seinfeld, 2012). Many 
scientific aspects of these processes are uncertain. Emissions budgets of methane and other VOCs (volatile organic compounds) are poorly constrained and frequently do not agree with inventory estimates (Brandt et al., 2014; Miller et al., 2013). Many variables can affect the composition of emissions, including well life-cycle stage, extraction techniques, whether the well is producing oil or gas, and diverse infrastructure/equipment components (Moore et al., 2014; Litovitz et al., 2013; Allen et al., 2013). Wintertime ozone events, while sharing some similarities with ozone formation typically seen in urban areas during the summer, occur in different meteorological and chemical conditions and have attracted several recent measurement and modeling investigations (Schnell et al., 2009; Kotamarthi and Holdridge, 2007; Carter and Seinfeld, 2012; Edwards et al., 2013, 2014).

The Uintah Basin, located in northeastern Utah, is a region of intense oil and natural gas extraction activity. Approximately 4000 active oil-producing and 6500 gas-producing wells are located in a $10000 \mathrm{~km}^{2}$ area, with an additional 1000 wells added each year (Utah Oil and Gas, 2014). In January and February of 2012-2014, a suite of chemical and meteorological instrumentation was deployed at Horse Pool, a remote site in the eastern part of the basin. Little active photochemistry was observed in 2012, but in 2013 ground snow cover was accompanied by several sustained periods of strong temperature inversion. Temperature inversions trap ozone precursors emitted by oil and natural gas activity (VOCs and $\mathrm{NO}_{x}$ ) and ozone close to the surface. Increased actinic flux from reflective snow cover contributes to heightened ozone-producing photochemistry (Edwards et al., 2014). The gradual buildup of VOCs and ozone during a period of several days these conditions can lead to very high mixing ratios - in this case, up to $5 \mathrm{ppmC}$ nonmethane hydrocarbon and $150 \mathrm{ppb}$ ozone. VOCs are a fundamental component of the photochemistry that occurred during these events, so it is important to quantify (1) the rate at which VOCs are emitted from primary sources ("emission rate"), (2) the source composition of the VOC mixture ("emission ratios"), and (3) the degree of VOC oxidation.

In this paper, we analyze the photochemical aging of VOCs during an ozone formation period in 2013. We first examine primary, aromatic VOCs with a method that considers reaction with $\mathrm{OH}$ and constant primary emission. This analysis provides information on the emission rate and emission ratios of these VOCs, and the typical daily concentration of $\mathrm{OH}$. We next investigate oxygenated VOCs with a method that includes production and loss via $\mathrm{OH}$ chemistry and loss to photolysis. This approach identifies oxygenated VOCs with substantial primary sources and suggests rates of carbonyl formation from photochemistry. Finally, we calculate the organic carbon mass balance of primary and product species. This defines overall VOC speciation and determines the fraction of product species measured with the Horse Pool instrumentation.

\section{Methods}

\subsection{Measurement site and instrumentation.}

The Horse Pool site is located in the central eastern part of the Uintah Basin, approximately $30 \mathrm{~km}$ south of Vernal, Utah. Meteorological, gas, and particle-phase measurements were deployed concurrently at the site from 15 January to 29 February 2012, 23 January to 22 February 2013, and 15 January to 13 February 2014. Data referenced in this paper are primarily from a proton-transfer-reaction massspectrometer (PTR-MS), deployed in both 2012 and 2013, and a gas chromatograph with flame ionization detection (GC-FID), deployed in 2013. Measurements from 2014 are not discussed in this analysis.

PTR-MS uses chemical ionization with $\mathrm{H}_{3} \mathrm{O}^{+}$ions to selectively detect VOCs (de Gouw and Warneke, 2007). The technique is particularly sensitive to aromatic and small oxygenated VOCs but cannot detect small alkanes due to their low proton affinity. The instrument deployed at Horse Pool uses a quadrupole mass filter with unit mass resolution that scans through a set of selected ions every $38 \mathrm{~s}$. Data are averaged to a $1 \mathrm{~min}$ timescale. Calibrated measurement accuracy is generally better than $20 \%$, with a precision of $10 \%$. The instrument is not able to distinguish between isomers; e.g., a measurement of $\mathrm{C} 8$ aromatics comprises the sum of ethylbenzene, $o-, m-$, and $p$-xylenes. Comparison with a high-resolution PTR-time-of-flight spectrometer operated by the University of Wyoming (Warneke et al., 2015) indicates negligible contribution from isobaric compounds (e.g., benzaldehyde).

The GC-FID deployed at Horse Pool resolves C2-C7 saturated and unsaturated hydrocarbons. Ambient air passes through water and carbon dioxide traps, then into a liquid nitrogen cryogenic VOC trap. VOCs are captured in the cryogenic trap for 5 min every half hour. After the fiveminute sampling period, compounds are injected onto a $50 \mathrm{~m}$ $\mathrm{Al}_{2} \mathrm{O}_{3} / \mathrm{KCl}$ PLOT column and analyzed using flame ionization detection. The accuracy and precision are dependent on compound and sample flow rate, but are generally $<20$ and $<5 \%$, respectively. The instrument has been previously described in more detail by Kuster et al. (2004).

Other measurements used in this paper include gaschromatography mass-spectrometry (GC-MS) operated in 2012 (Gilman et al., 2010), methane cavity ring-down spectroscopy (CaRDS, Picarro) operated in 2013 (Crosson, 2008), organic aerosol via quartz filter collection/thermal desorption in 2013 (Bates et al., 2004), snow organic carbon using a Shimadzu TOC-VCSH instrument in 2013, and organic peroxy nitrate (PAN) species by chemical ionization mass spectrometry (Slusher et al., 2004). Some sulfur-containing species were measured ( $\mathrm{Li}$ et al., 2014) but are not discussed in this manuscript. Further details on sampling methods and conditions, meteorological measurements, and calibrations are described in a summary 


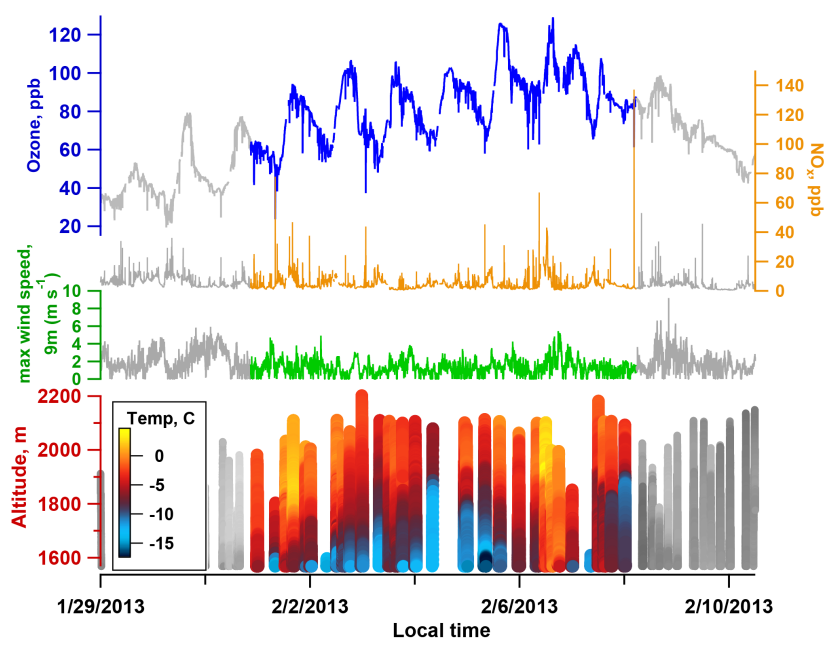

Figure 1. Ozone formation event and analysis period selection. The analyzed period (colored) was selected to avoid high wind events on 31 January and 8 February (center) and include strong temperature inversions (bottom) to minimize mixing of VOCs in or out of the basin. Meteorological data courtesy of NOAA Physical Sciences Division. Temperature data from tethered balloon sonde operated by NOAA Global Monitoring Division.

report (Uintah Basin: 2013 Winter Ozone Study: Final Report; available at http://www.deq.utah.gov/locations/U/ uintahbasin/ozone/strategies/studies/UBOS-2013.htm).

\subsection{Data treatment}

A stagnation event associated with high levels of ozone formation occurred from 29 January to 10 February 2013. A subset of this period, 31 January 2013 20:48 (LT) through 8 February 2013 05:29, is analyzed here (Fig. 1). This period captures the majority of the ozone formation event, is characterized by a strong temperature inversion, and avoids periods of higher wind on 31 January and 8 February. Selecting these meteorological conditions minimizes changes in VOC concentrations and ratios due to mixing into or out of the basin.

Primary hydrocarbons and oxygenated compounds investigated are listed in Table 1. The majority of analysis was applied to compounds measured by PTR-MS. The fast time resolution of this instrument $(1 \mathrm{~min})$ allows for the separation of plumes of VOCs from nearby sources from the more regionally widespread, accumulated emissions in the basin. Additionally, restricting analyzed compounds to a single instrument helps eliminate instrumental variation. Additional compounds from the GC-FID data set were used to investigate the balance of primary and secondary species.

Concentrations of VOCs during an inversion event displayed rapid, diurnal, and multi-day variability (Fig. 2). Some of this variability is attributable to meteorology (such as changes in boundary layer height during the day, or tempo- rary shifts in wind direction bringing pollution from nearby sources), and some to chemistry, but the relative contributions can be difficult to separate. Analysis of ratios of VOCs provides a way to isolate the effects of chemistry from meteorology. This is a common and flexible approach: applications have included determining the photochemical age of urban emissions (Roberts et al., 1984; de Gouw et al., 2005), quantifying halogen chemistry in arctic air (Jobson et al., 1994), and identifying contributions from oil and natural gas operations to ambient pollution (Gilman et al., 2013).

Measurements of primary compounds by PTR-MS showed frequent 1-3 min duration episodes with very high mixing ratios, at least $50 \%$ higher than short-term average concentration. These spikes signify interception of plumes of un-aged emissions and are not representative of the bulk air composition at the Horse Pool site. An hourly running median was applied to separate longer-term variability from transitory primary emissions (Fig. 2). For consistency, an hourly running median was also applied to oxygenated compounds. The ratio of each VOC to benzene was then determined. Benzene is a well-calibrated compound with few interferences on the PTR-MS; additionally, good agreement with other instrumentation (GC-FID and PTR-ToF) at the site affords a high level of confidence in this measurement (Warneke et al., 2015).

\section{Results and discussion}

\subsection{Primary compounds}

Primary compounds are defined as those species that are directly emitted and not formed by photochemistry. The rate of change with time of a single, primary VOC can be written as

$$
\frac{\mathrm{d}[\mathrm{VOC}]}{\mathrm{d} t}=P_{\mathrm{VOC}}-k_{\mathrm{VOC}}[\mathrm{OH}][\mathrm{VOC}]-\sum D_{i}[\mathrm{VOC}],
$$

where $P_{\mathrm{VOC}}$ is the emission rate of the VOC and $k_{\mathrm{VOC}}$ is the rate constant for the reaction of the $\mathrm{VOC}$ with $\mathrm{OH} . P_{\mathrm{VOC}}$ is a volumetric input with units of molecules per cubic centimeter per second and describes how direct emission increases observed VOC concentrations. The only chemical loss term included is reaction with $\mathrm{OH}$, the major oxidizing radical in this environment. Previous modeling has suggested that VOC reactions with other radicals, such as $\mathrm{Cl}^{\circ}$, were negligible in comparison to reactions with $\mathrm{OH}$ (Edwards et al., 2014). Additionally, reaction rates of the primary species considered here (C6-C10 aromatics) with $\mathrm{O}_{3}$ and $\mathrm{NO}_{3}$ are at least several orders of magnitude lower than reaction rates with $\mathrm{OH}$ (Atkinson and Arey, 2003). $D_{i}$ are rate constants for firstorder loss processes; e.g., deposition, dilution, photolysis, etc. If two VOCs, "A" and "B", behave according to Eq. (1), we can derive the rate of change of their ratio ([A] / [B]) as follows: 
Table 1. Compounds analyzed. The italicized data are 1 standard deviation $(1 \sigma)$ of the average mixing ratio, as indicated in the units - ppbv $(1 \sigma)$ - beneath the "average mixing ratio" header.

\begin{tabular}{|c|c|c|c|}
\hline \multirow[b]{2}{*}{ PTR-MS } & \multirow[t]{2}{*}{$\begin{array}{c}\text { OH rate constant } \\
10^{-12} \mathrm{~cm}^{3} \text { molecule }{ }^{-1} \mathrm{~s}^{-1}\end{array}$} & \multicolumn{2}{|c|}{$\begin{array}{l}\text { Average mixing ratio } \\
\operatorname{ppbv}(1 \sigma)\end{array}$} \\
\hline & & & \\
\hline \multicolumn{4}{|l|}{ Primary compounds } \\
\hline Benzene & 1.22 & 3.30 & $(1.92)$ \\
\hline Toluene & 5.63 & 4.00 & $(2.76)$ \\
\hline C8 aromatics & $16.4^{\mathrm{a}}$ & 1.74 & $(1.36)$ \\
\hline C9 aromatics & $16.9^{\mathrm{a}}$ & 0.365 & $(0.271)$ \\
\hline $\mathrm{C} 10$ aromatics & $24.2^{\mathrm{a}}$ & 0.071 & $(0.055)$ \\
\hline \multicolumn{4}{|l|}{ Secondary compounds } \\
\hline Acetaldehyde & 15.0 & 4.27 & $(2.39)$ \\
\hline 2-butanone (MEK) & 1.22 & 2.81 & $(1.69)$ \\
\hline Acetone & 0.17 & 7.97 & $(4.69)$ \\
\hline Formic acid & $0.37^{\mathrm{b}}$ & 2.56 & $(1.43)$ \\
\hline \multicolumn{4}{|c|}{ Compounds with mixed or undetermined source } \\
\hline Methanol & 0.94 & 44.9 & $(33.4)$ \\
\hline Formaldehyde & 9.37 & 3.71 & $(1.49)$ \\
\hline \multicolumn{4}{|l|}{ GC-FID } \\
\hline \multicolumn{4}{|l|}{ Primary compounds } \\
\hline Ethane & 0.248 & 300 & $(169)$ \\
\hline Propane & 1.09 & 140 & $(78.6)$ \\
\hline$n$-butane & 2.36 & 48.0 & $(26.9)$ \\
\hline 2-methylpropane & 2.12 & 30.3 & $(17.1)$ \\
\hline$n$-pentane & 3.80 & 18.8 & $(10.5)$ \\
\hline 2-methylbutane & 3.60 & 20.9 & $(11.8)$ \\
\hline 2,2-dimethylpropane & 0.825 & 0.306 & $(0.181)$ \\
\hline$n$-hexane & 5.20 & 8.32 & $(4.65)$ \\
\hline Sum of 2- and 3-methylpentane & 5.20 & 6.62 & $(3.99)$ \\
\hline 2,2-dimethylbutane & 2.23 & 0.467 & $(0.294)$ \\
\hline Methylcyclopentane & 6.90 & 3.65 & $(2.27)$ \\
\hline$n$-heptane & 6.76 & 4.00 & $(2.30)$ \\
\hline Methlcyclohexane & 9.64 & 6.74 & $(4.17)$ \\
\hline Ethyne & 0.88 & 0.796 & $(0.40)$ \\
\hline Ethene & 8.52 & 2.05 & $(1.06)$ \\
\hline Propene & 26.3 & 0.171 & $(0.0724)$ \\
\hline
\end{tabular}

${ }^{a}$ Rate constants determined in this work. ${ }^{\mathrm{b}}$ Anglada (2004). All other OH rate constants from Atkinson and Arey (2003).

$\operatorname{ratio}(t)=\frac{[\mathrm{A}](t)}{[\mathrm{B}](t)}$

Using the partial derivatives of $\operatorname{ratio}(t)$ with respect to [A] and $[\mathrm{B}]$, the rate of change of the ratio is

$$
\frac{\mathrm{d}(\text { ratio })}{\mathrm{d} t}=\frac{1}{[\mathrm{~B}]} \frac{\mathrm{d}[\mathrm{A}]}{\mathrm{d} t}-\frac{[\mathrm{A}]}{[\mathrm{B}]^{2}} \frac{\mathrm{d}[\mathrm{B}]}{\mathrm{d} t}
$$

Then, substituting Eq. (1) for $\mathrm{dA} / \mathrm{d} t$ and $\mathrm{dB} / \mathrm{d} t$, we arrive at

$$
\begin{aligned}
\frac{\mathrm{d}(\text { ratio })}{\mathrm{d} t} & =\frac{P_{\mathrm{B}}}{[\mathrm{B}]}(\mathrm{ER}-\text { ratio })+(\text { ratio })[\mathrm{OH}]\left(k_{\mathrm{B}}-k_{\mathrm{A}}\right) \\
& +\sum \text { (ratio) }\left(D_{i \mathrm{~B}}-D_{i \mathrm{~A}}\right) .
\end{aligned}
$$

The primary emission rate $\left(P_{\mathrm{B}}\right)$, emission ratio $(\mathrm{ER})$, and the concentration of $\mathrm{OH}$ are unknown. The emission ratio (ER $\left.=P_{\mathrm{A}} / P_{\mathrm{B}}\right)$ is the ratio of two VOCs in fresh emissions (time $t=0$ ) and is a measure of source composition. We consistently used benzene as the denominator in the ratio, so that $[\mathrm{B}]=$ [benzene], $P_{\mathrm{B}}$ is the emission rate of benzene, ER is 

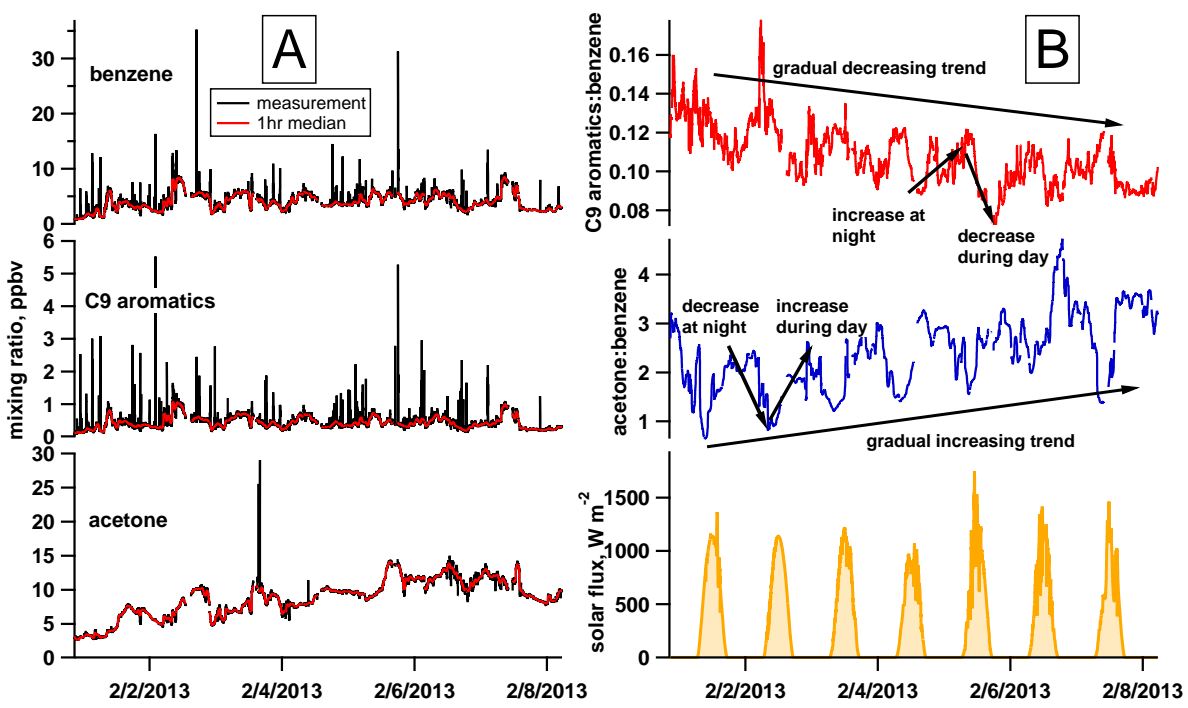

Figure 2. Description of trends in VOC concentrations and ratios. (a) Mixing ratios of benzene, C9 aromatics, and acetone (black), and a $1 \mathrm{~h}$ running median to isolate spikes (red). (b) Ratios of C9 aromatics (top) and acetone (center) to benzene. Sunlight intensity is shown beneath. The spikes visible in (a) have been removed to isolate longer-term trends in VOC behavior (discussed in text).

the emission ratio of a VOC to benzene, and so on. Meteorological data and the measured ambient mixing ratio of benzene were used to determine the number density of benzene ([B]) as a function of time. These values were referenced directly when applying Eq. (2c).

C6-C10 aromatic VOCs were selected for analysis of primary compounds because they have readily identifiable parent masses, they are sensitively detected by PTR-MS, and have a relatively wide range of reactivity with $\mathrm{OH}$ $\left(k_{\mathrm{OH}}=1.22 \times 10^{-12} \mathrm{~s}^{-1}\right.$ to $\left.56 \times 10^{-12} \mathrm{~s}^{-1}\right)$. Application of this analysis to VOCs measured by PTR-MS using Eq. (2c) includes the following assumptions.

1. For each first-order loss process, rate constants are nearly identical for aromatic compounds $\left(D_{i \mathrm{~A}}=D_{i \mathrm{~B}}=\right.$ $\left.D_{i}\right)$. These loss processes include mixing out of the basin, photolysis, and deposition. Mixing is dependent on dynamics and not on chemical characteristics, so mixing loss rate constants should be identical for all VOCs with the same vertical concentration profile $\left(D_{\text {mixing,B }}-D_{\text {mixing,A }}=0\right)$. We saw no evidence of differences in vertical gradients of aromatic species at Horse Pool. As concentrations of VOCs in the background atmosphere were considerably smaller than VOC concentrations inside the basin, changes in VOC ratios due to mixing in of background air are negligible. Integrated UV absorption cross sections of C6-C10 aromatic hydrocarbons are small and similar to one another (Etzkorn et al., 1999), so $D_{\text {photolysis,B }}-D_{\text {photolysis,A }}$ is likely negligible compared to primary emission and reaction with $\mathrm{OH}$. The same argument can be made for wet or dry deposition, $D_{\text {deposition,B }}-D_{\text {deposition,A }} \cong 0$, as monocyclic aromatic compounds are structurally simi- lar and have small solubilities in water. The terms $D_{i \mathrm{~B}}$ and $D_{i \mathrm{~A}}$ can therefore be eliminated.

2. Primary VOC emission rate and emission ratios are constant in time and similar in composition across the basin - we cannot confidently parameterize a more complicated emissions scenario with available data, nor is there any evidence supporting or reason to assume a change in emissions with time of day.

3. Finally, on an hourly scale, we assume that compounds are well mixed. The latter assumptions are supported by aircraft measurements in January-February 2013, which found elevated VOC concentrations with similar ratios in all parts of the basin, including regions with varying intensities and types of fossil fuel extraction activity (Oltmans et al., 2014). The time period analyzed, characterized by a strong temperature inversion and light winds (Fig. 1), was specifically selected to support these assumptions.

\subsubsection{Emission rates and ratios}

The analysis is first applied to nighttime data only (any points where solar radiation is zero), to estimate $P_{\mathrm{B}}$ and ER. During the night, $\mathrm{OH}$ is close to zero and Eq. (2c) reduces to

$$
\frac{\mathrm{d}(\text { ratio })}{\mathrm{d} t}=\frac{P_{\mathrm{B}}}{[\mathrm{B}]}(\mathrm{ER}-\text { ratio })
$$

This method, using only nighttime data, reduces the number of free variables. It completely separates primary emission from $\mathrm{OH}$ chemistry. Additionally, it allows for the use of $\mathrm{C} 9$ 
Table 2. Primary compound results.

\begin{tabular}{|c|c|c|c|c|c|}
\hline Compound & $\begin{array}{l}\text { Emission ratio } \\
\text { to benzene by mol }\end{array}$ & $\begin{array}{r}\text { Benzene } \\
\text { emission rate } \\
10^{5} \text { molecule } \mathrm{cm}^{-3} \mathrm{~s}^{-1}\end{array}$ & $\begin{array}{r}{[\mathrm{OH}] \text { avg. }} \\
10^{5} \text { molecule } \mathrm{cm}^{-3}\end{array}$ & $\begin{array}{r}\text { OH rate } \\
\text { constant } \\
10^{-12} \mathrm{~cm}^{3} \text { molecule }{ }^{-1} \mathrm{~s}^{-1}\end{array}$ & $\begin{array}{l}R^{2}-\text { full time } \\
\text { series best fit }\end{array}$ \\
\hline Toluene & 1.5 & 4.5 & 2.66 & 5.63 & 0.242 \\
\hline $\mathrm{C} 8$ aromatics & 0.82 & 4.1 & 1.86 & 16.4 & 0.421 \\
\hline C9 aromatics & 0.18 & 3.9 & & 16.9 & 0.614 \\
\hline $\mathrm{C} 10$ aromatics & 0.042 & 3.8 & & 24.2 & 0.273 \\
\hline
\end{tabular}

Table 2 includes results from the nighttime-data only best fit (emission ratios, benzene emission rate), and the full time series (including both day and night) best fit ([OH], $k_{\mathrm{OH}}$, and $R^{2}$ ).

and $\mathrm{C} 10$ aromatics measurements, as the $\mathrm{OH}$ rate constants for these groups are not well constrained.

The measured ratios of $\mathrm{C} 7, \mathrm{C} 8, \mathrm{C} 9$, and $\mathrm{C} 10$ aromatics to benzene were described using a best fit of Eq. (3) to the data. The free parameters in this fit are $P_{\mathrm{B}}$ and ER. A best fit was determined separately for each of the four aromatic ratios, providing four, similar, independent estimates of $P_{\mathrm{B}}$ (Fig. 3) and four emission ratios to benzene (Table 2). We evaluate the fit by comparing emission ratios to literature values and the composition of plumes from nearby sources and, second, by comparing emission rate to an independent estimate.

The derived emission ratios from this analysis represent an averaged source composition of all point sources contributing VOCs to well-mixed air. In Fig. 4, the derived emission ratios are compared to three other measurements of source composition in the Uintah Basin: (1) mobile laboratory measurements taken at individual well pads in 2012 (Warneke et al., 2014), (2) ambient measurements taken at Horse Pool in 2012 (Warneke et al., 2014), and (3) 2013 VOC enhancement ratios in spikes above a $1 \mathrm{~h}$ running median (discussed above). These spikes are likely plumes of fresh emissions from nearby well pads. The fastest-reacting C10 aromatic (1,2,4-trimethylbenzene) had a peak daytime chemical lifetime against $\mathrm{OH}$ of about $30 \mathrm{~min}$. Seven other well pads were within $500 \mathrm{~m}$ of the Horse Pool site; given average wind speed $\left(1.6 \mathrm{~m} \mathrm{~s}^{-1}\right)$, this corresponds to a $5 \mathrm{~min}$ transport time - much shorter than the chemical lifetime of any of the analyzed aromatic species. All three measurements are separated into gas-producing and oil-producing well contributions; in mobile lab data, by type of well pad sampled; and in Horse Pool data, by correlation with wind direction (Warneke et al., 2014).

There is a clear distinction between oil and gas sources. The difference grows with carbon number; i.e., gas producing-wells emit a lighter mixture of VOCs. Emission ratios suggested by our analysis suggest significant contribution from both oil and gas sources. In addition to the oil/gas distinction, there is a large range of variability in source composition of aromatic species. This variability is difficult to represent in bulk emissions estimates and models. Together with supporting evidence from aircraft that emissions

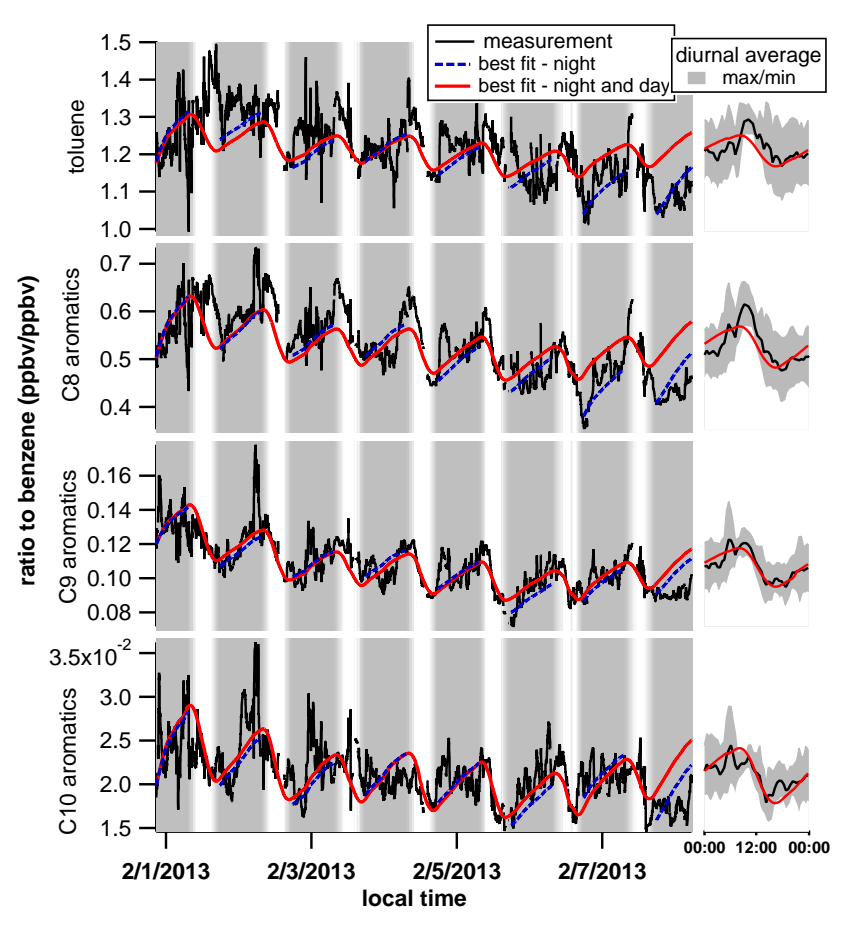

Figure 3. Aromatic compound ratios and best fit to nighttime data (blue) and both night and day data (red). The background is colored by sunlight intensity to distinguish day and night. For reproducibility, the initial ratio for each night was chosen from the 10th percentile of points during the first $2 \mathrm{~h}$ of the evening. In practice, best-fit parameters were largely insensitive to the initial ratio, as long as the selected initial ratio was close to measurements during the early part of the night. A diurnal average is shown to the right.

were reasonably well mixed across the basin (Oltmans et al., 2014), our analysis provides an independent measure of average emissions composition.

The average benzene emission rate was $4.1 \pm 0.4 \times 10^{5}$ molecules $\mathrm{cm}^{-3} \mathrm{~s}^{-1}$. To evaluate this emission rate estimate, we compare to basin-wide methane emission measurements conducted by aircraft in 2012 (Karion et al., 2013). To our knowledge, this is the only recent top-down emissions estimate for the Uintah Basin. Karion et al. determined that basin-wide methane emissions were 


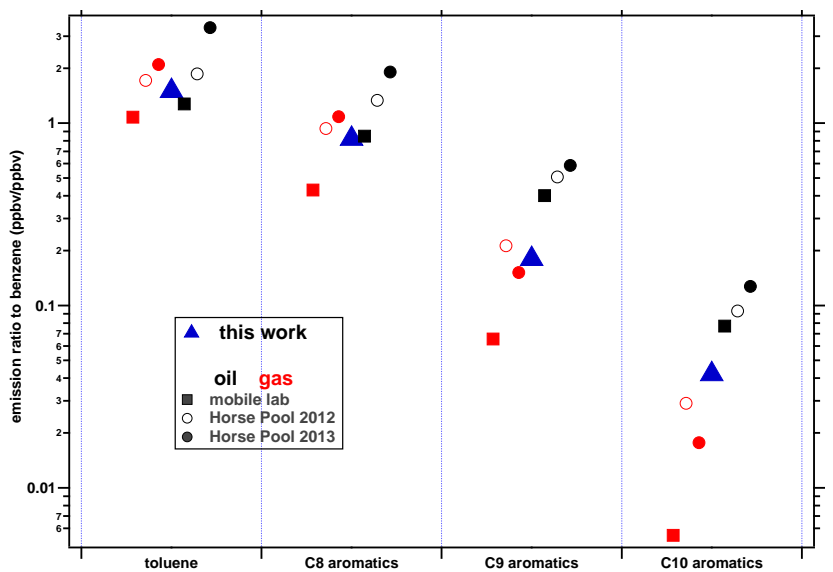

Figure 4. Comparison of emission ratio estimates. Emission ratio estimates from this analysis (blue triangle) give an average emission ratio that is partway between the oil and gas sources.

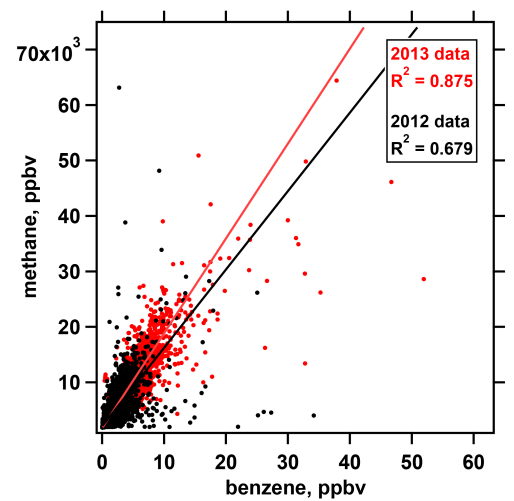

Figure 5. Correlation between methane and benzene for all data taken in 2013 (red) and 2012 (black).

$55 \pm 15 \times 10^{3} \mathrm{~kg} \mathrm{~h}^{-1}$. To compare a volume-normalized estimate (molecules benzene $\mathrm{cm}^{-3} \mathrm{~s}^{-1}$ ) to the whole-basin estimate $\left(\mathrm{kg}\right.$ methane $\mathrm{h}^{-1}$ ), we need (1) the emission ratio of methane to benzene and (2) the total volume of the polluted layer during the 2013 ozone episode.

A strong correlation between methane and benzene is apparent from ground site measurements at Horse Pool in 2012 and 2013 (Fig. 5). Aircraft flask samples taken in 2013 suggest that the methane: benzene ratio is independent of location in the basin - it was similar in both the eastern gas field and western oil field (Oltmans et al., 2014). The methane: benzene emission ratio was approximated from 2012 measurements and 2013 plumes $\left(\mathrm{ER}=1330 \pm 80 \mathrm{ppbv}^{\mathrm{ppbv}}{ }^{-1}\right)$.

The polluted volume of the basin was determined from frequent ozonesonde measurements at a number of locations in the basin, as well as aircraft profiles. They showed wellmixed ozone concentrations up 1600-1700 m above sea level (100-200 m above ground level at Horse Pool), above which

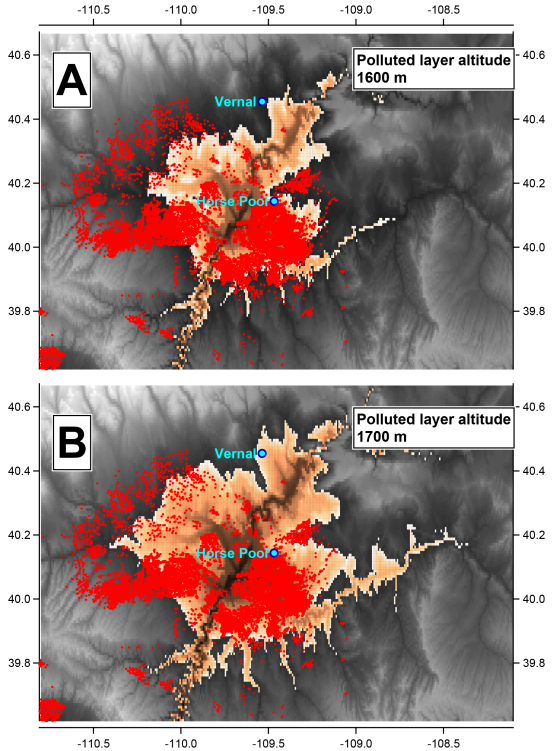

Figure 6. Topographical map of the Uintah Basin showing polluted region and well locations. Total relief is from $1398 \mathrm{~m}$ above sea level to $3627 \mathrm{~m}$. The bright ( $\tan )$ region shows the area of the polluted region assuming the polluted layer extends to $1600 \mathrm{~m}$ (a) or $1700 \mathrm{~m}$ above sea level (b). Locations of producing oil and gas wells are marked in red.

mixing ratios decreased sharply (Oltmans et al., 2014). Taking the terrain of the basin into account, we then integrate the volume of the basin from the surface to the mixing height. The uncertainty in the basin-wide methane emission estimate is dominated by the uncertainty in this volume, and we report the values determined from minimum and maximum polluted layer altitudes $(1600-1700 \mathrm{~m})$.

Using the methane:benzene ratio and the mixing volume of the basin, we derive an emission rate of (14$39) \times 10^{3} \mathrm{~kg}$ methane $\mathrm{h}^{-1}$. This is lower than the Karion et al. (2013) estimate, but of the same magnitude. An inspection of well locations in the basin shows that a significant fraction (40-50\%) of wells lie outside the polluted layer (Fig. 6). An aircraft flux measurement would have likely included contributions from these wells, whereas our analysis only included wells emitting inside the isolated polluted volume. A linear extrapolation based on the number of wells inside and outside the polluted volume suggests an emission rate of (2757) $\times 10^{3} \mathrm{~kg}$ methane $\mathrm{h}^{-1}$, which overlaps with the Karion et al. (2013) value. Although this estimate is considerably less precise than the aircraft flux measurement, it does confirm that the best-fit values of benzene emission rate are plausible.

\subsubsection{Concentration of $\mathrm{OH}$ radical}

The full time series (both day and night) was analyzed over the buildup period, using Eq. (2c). The primary emission term $\left(P_{\mathrm{B}}\right)$ and the emission ratio were fixed as determined 
from the nighttime best fits. The only remaining free variable is the concentration of $\mathrm{OH}$.

The calculation requires an $\mathrm{OH}$ rate constant $\left(k_{\mathrm{OH}}\right)$ for the aromatics. Measurements of C8 aromatics in 2013 were not isomerically resolved by PTR-MS and represent the sum of ethylbenzene and $o-, m$-, and $p$-xylenes. Speciated measurements of C8 aromatics by GC-MS were made in 2012, when photochemical aging of VOCs was less active and the bulk air composition more closely resembled primary emissions. The 2012 GC-MS measurements were used to compute a weighted average $\mathrm{OH}$ rate constant for the $\mathrm{C} 8$ aromatics group. The $\mathrm{OH}$ rate constants for individual species in this group are within a factor of 2.1 of the mean. The groups' C9 and C10 aromatics contain a much larger number of isomers, with a wider variance in $\mathrm{OH}$ rate constants. Not all these isomers were measured by GC-MS in 2012, and some of the $\mathrm{OH}$ rate constants are unknown. Therefore, the group average rate constant could not be constrained in the same way.

To parameterize the diurnal variation in $\mathrm{OH}$, we constrained $\mathrm{OH}$ to be proportional to solar actinic flux. It is well established that $[\mathrm{OH}]$ is strongly linearly correlated with UV light intensity (Hard et al., 1986; Rohrer and Berresheim, 2006). A best fit and an average value of $\mathrm{OH}$ was computed separately for both toluene and C8 aromatics according to Eq. (3) (shown in Fig. 3). Results are included in Table 2. The average of these two values was used as the concentration of $\mathrm{OH}$ in further analysis.

Using this $[\mathrm{OH}]$, the $k_{\mathrm{OH}}$ for $\mathrm{C} 9$ and $\mathrm{C} 10$ aromatics were allowed to vary. Best fits for the $\mathrm{C} 9$ and $\mathrm{C} 10$ aromatics were calculated and are shown in Fig. 3. The group average rate constants (Table 2) are within the range of values known for isomers of C9 and C10 aromatics. For C9 aromatics, the group average rate constant was determined to be $16.9 \mathrm{~cm}^{3}$ molecule ${ }^{-1} \mathrm{~s}^{-1}$; known values range from 5.3 (n-propylbenzene) to $56.7 \mathrm{~cm}^{3}$ molecule ${ }^{-1} \mathrm{~s}^{-1}(1,3,5-$ trimethylbenzene) (Atkinson and Arey, 2003). For C10 aromatics, the group average rate constant was determined to be $24.2 \mathrm{~cm}^{3}$ molecule ${ }^{-1} \mathrm{~s}^{-1}$; known values range from 4.5 ( $t$-butylbenzene) (Atkinson and Arey, 2003) to $55.5 \mathrm{~cm}^{3}$ molecule $\mathrm{s}^{-1} \mathrm{~s}^{-1}$ (1,2,4,5-tetramethylbenzene) (Aschmann et al., 2013). The average rate constant constrains group composition, and could be useful in future investigations of photochemical processing.

Knowledge of typical daily $\mathrm{OH}$ concentrations is crucial to understand photochemical processing of VOCs and ozone production. $\mathrm{OH}$ was not measured directly in 2013, but our analysis provides an estimate of $\mathrm{OH}$ exposure that is constrained by solar actinic flux and VOC measurements. $\mathrm{OH}$ peaked daily at $1 \times 10^{6}( \pm 21 \%)$ molecule $\mathrm{cm}^{-3}$, which is low compared to urban areas affected by photochemical smog with typical $\mathrm{OH}$ concentrations of (510) $\times 10^{6}$ molecule $\mathrm{cm}^{-3}$ (Shirley et al., 2006). We compare to an independent estimate of [OH] in 2013 using the Master Chemical Mechanism v.3.2 (MCM) framework (Edwards

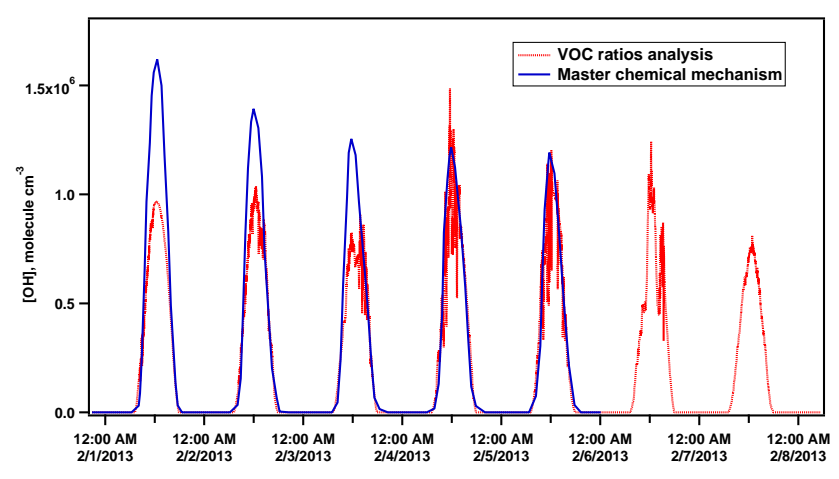

Figure 7. Comparison of $\mathrm{OH}$ with the Master Chemical Mechanism prediction. There is good agreement between the $\mathrm{MCM} \mathrm{OH}$ and $\mathrm{OH}$ determined from our analysis.

et al., 2014). The MCM OH estimate is generated using more than 12000 explicit reactions comprising degradation schemes for nearly all hydrocarbons measured at the Horse Pool site and has been applied previously to photochemistry in the Uintah Basin (Edwards et al., 2013, 2014). The agreement between our model and the MCM estimate in peak daytime concentration is within a factor of 1.7 overall and differs by only $2 \%$ on 5 February 2013 (Fig. 7). The agreement is especially good considering that $\mathrm{OH}$ values in our analysis are constrained by measured photolysis rates and a single scaling factor, so it cannot generate the multi-day trend seen in the MCM calculation. This excellent agreement substantiates the chemistry described by the MCM model.

\subsection{Oxygenated compounds}

Oxygenated compounds may also have photochemical sources. For these species, the change in concentration with time is controlled by the production rate via photochemistry, loss to reaction with $\mathrm{OH}$, and first-order loss processes such as mixing, photolysis and deposition. The rate of change can be written similarly to Eq. (1):

$$
\begin{aligned}
\frac{\mathrm{d}[\mathrm{VOC}]}{\mathrm{d} t} & =\text { Yield } \cdot k_{\text {precursors }}[\mathrm{OH}][\text { precursors }] \\
& -k_{\mathrm{VOC}}[\mathrm{OH}][\mathrm{VOC}]-D[\mathrm{VOC}] .
\end{aligned}
$$

Here [precursors] is the sum concentration of all precursor species, Yield is the fraction of reactions with $\mathrm{OH}$ that form the product compound, and $k_{\text {precursors }}$ is the weighted average $\mathrm{OH}$ rate constant of precursor species. Again, $D$ represents first-order loss processes. The oxygenated species considered here are acetaldehyde, acetone, 2-butanone (MEK), formic acid, methanol, and formaldehyde. 
Table 3. Oxygenated compound results.

\begin{tabular}{|c|c|c|c|c|}
\hline Compound & $\begin{array}{r}\text { Benzene } \\
\text { emission rate } \\
10^{5}{\text { molecule } \mathrm{cm}^{-3} \mathrm{~s}^{-1}} \text {. }\end{array}$ & $\begin{array}{r}\text { Formation } \\
\text { rate constant } \\
10^{-11} \mathrm{~cm}^{3} \text { molecule }{ }^{-1} \mathrm{~s}^{-1}\end{array}$ & $\begin{array}{r}R^{2} \\
\text { (daytime data) }\end{array}$ & $\begin{array}{l}\text { Photolysis } \\
\text { rate constant } \\
\mathrm{s}^{-1}\end{array}$ \\
\hline Acetaldehyde & 4.91 & 7.36 & 0.667 & $1.2 \times 10^{-6}($ Martinez et al., 1992$)$ \\
\hline Formic acid & 6.04 & 3.30 & 0.414 & $1.0 \times 10^{-6}($ estimated $)$ \\
\hline Acetone & 4.46 & 8.72 & 0.775 & $5.0 \times 10^{-8}($ McKeen et al., 1997) \\
\hline MEK & 4.97 & 3.42 & 0.787 & $3.6 \times 10^{-6}$ (Martinez et al., 1992) \\
\hline Methanol & 1.34 & & & (day analysis not performed) \\
\hline Formaldehyde & 0.90 & & & (day analysis not performed) \\
\hline
\end{tabular}

As with Eq. (2c), the rate of change of the ratio of a photochemically produced compound to benzene is

$$
\begin{aligned}
\frac{\mathrm{d}(\text { ratio })}{\mathrm{d} t} & =\text { Yield } \cdot k_{\text {precursors }}[\mathrm{OH}] \cdot R_{\mathrm{PB}} \\
& -(\text { ratio }) \cdot\left([\mathrm{OH}]\left(k_{\mathrm{prod}}-k_{\mathrm{B}}\right)+J+\frac{P_{\mathrm{B}}}{[\mathrm{B}]}\right), \\
& =\lambda_{f} \cdot[\mathrm{OH}]-(\text { ratio }) \\
& \cdot\left([\mathrm{OH}]\left(k_{\text {prod }}-k_{\mathrm{B}}\right)+J+\frac{P_{\mathrm{B}}}{[\mathrm{B}]}\right) .
\end{aligned}
$$

$R_{\mathrm{PB}}$ is the ambient ratio of precursor species to benzene, $k_{\text {prod }}$ and $k_{\mathrm{B}}$ are the $\mathrm{OH}$ rate constants of the product species and benzene, and $J$ is the photolysis rate constant of the product species. Here we again assume that other first-order processes, mixing and deposition, are not significantly different between the oxygenated VOCs and benzene. On the other hand, most of these compounds contain a carbonyl functional group, and photolysis rates could be significant. $J$ was set proportional to solar actinic flux and scaled to photolysis constants from the literature (values and literature sources are given in Table 3). We also assume that the only source of these species is photochemistry; i.e., they are not emitted directly from primary sources. Methanol and formaldehyde are included in this section as they are oxygenated species. However, the high observed mixing ratios of methanol and formaldehyde (Table 1), previous modeling work (Edwards et al., 2014), and knowledge of industry practices indicates that these two species also have direct (primary) sources. We first analyzed methanol and formaldehyde assuming solely photochemical sources, to investigate the extent to which secondary formation can explain their behavior. We then modified the analysis to consider primary emission of these species. Methanol and formaldehyde are discussed separately in the analysis (below).

As the relative amounts of precursor species and their product yields were unknown, yield, $k_{\text {precursors }}$, and $R_{\mathrm{PB}}$ were bundled into a single free variable, $\lambda_{\mathrm{f}}$ (formation rate constant). The term $R_{\mathrm{PB}}$ requires further discussion. The analysis of primary compounds (above) shows that the ratios of C7-C10 aromatics to benzene are highly variable and depend on photochemical exposure. $R_{\mathrm{PB}}$, the ratio of precursor

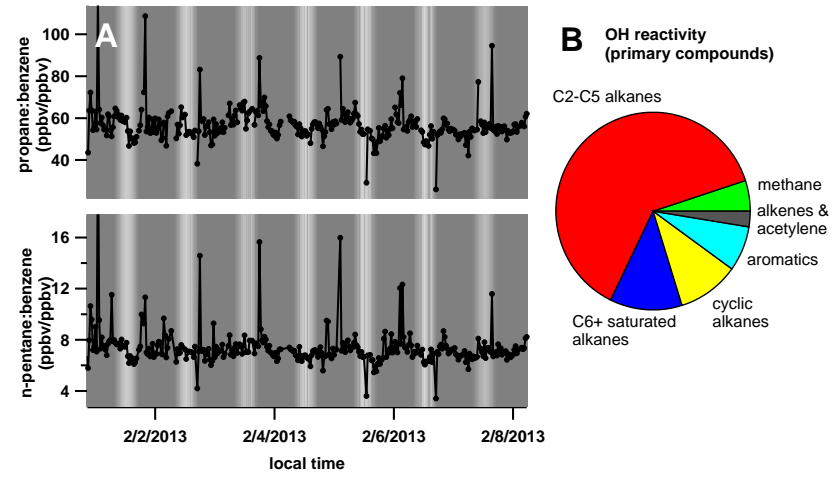

Figure 8. (a) Because of their slow reaction rates with $\mathrm{OH}$, the ratios of C2-C5 alkanes to benzene did not have high diurnal variability and did not change substantially from beginning to end of the stagnation event (propane and $n$-pentane measured by GC-FID are shown as representatives). (b) However, because of their high mixing ratios, these species account for a large fraction $(\sim 70 \%)$ of primary hydrocarbon-OH reactions.

species to benzene, should also change over time. However, in applying Eq. (5b), we have simplified analysis by treating $R_{\mathrm{PB}}$ as approximately constant. By volume, the dominant VOCs measured at Horse Pool were C1-C5 alkanes. These compounds react more slowly with $\mathrm{OH}$ than $\mathrm{C} 7-\mathrm{C} 10$ aromatics. Reaction with $\mathrm{OH}$ has a proportionally smaller effect on their concentrations and, indeed, ratios of these compounds to benzene show less diurnal variability (Fig. 8a). Despite how slowly these compounds react with $\mathrm{OH}$, the very large concentration of these compounds means that $\mathrm{C} 2-\mathrm{C} 5$ alkanes account for most of the reactions between $\mathrm{OH}$ and VOCs, and are the most important precursor compounds (Fig. 8b). We can therefore use the simplifying approximation of constant precursor : benzene ratio.

Again, the analysis was first applied to nighttime data only. During the night, Eq. (5b) reduces to

$\frac{\mathrm{d}(\text { ratio })}{\mathrm{d} t}=-($ ratio $)\left(\frac{P_{\mathrm{B}}}{[\mathrm{B}]}\right)$.

Using Eq. (6), a best fit was calculated for acetaldehyde, formic acid, acetone, MEK, methanol, and formaldehyde 


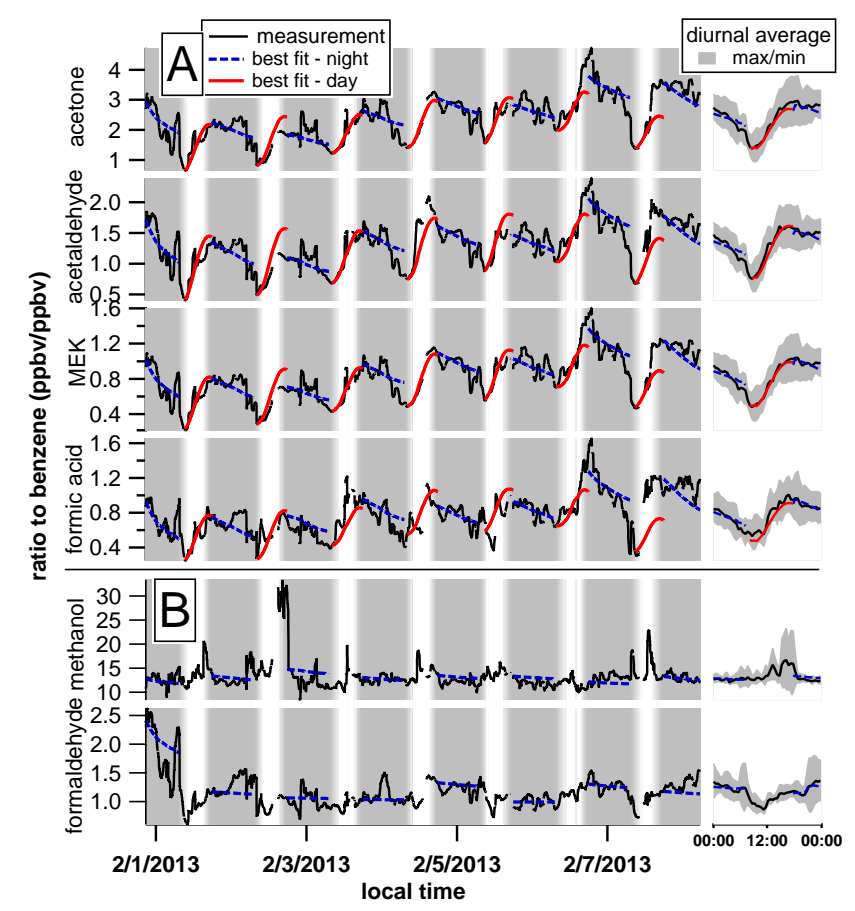

Figure 9. Analysis results for oxygenated compounds. Measured ratio is in black, nighttime best fit in blue, and daytime best fit in red. (a) The best fit is able to reproduce VOC trends during the day for acetone, MEK, acetaldehyde, and formic acid. (b) The best fit does not reproduce nighttime variability or trends in methanol and formaldehyde, which may have substantial primary sources uncorrelated with benzene.

(Fig. 9), providing six values of the primary benzene emission rate $\left(P_{\mathrm{B}}\right)$ (Table 3$)$.

The best-fit functions to acetone, acetaldehyde, formic acid, and MEK for nighttime data only were able to predict a decreasing trend in the ratio of VOC : benzene but did not replicate the strong decrease in ratio towards the end of the night. Primary emission of benzene during the night could only account for a portion of the decrease, signifying an additional oxygenate removal process not included in Eq. (6). A possible candidate is increased deposition of oxygenates. Including a free first-order deposition variable did not significantly affect model output, suggesting a complex process increasing in strength during the night. One possibility is deposition on ice crystals. Surfaces, including the sampling inlet, typically gained a thick coating of ice rime during the night, creating additional surface area available for deposition. This process would also affect polar oxygenated species much more than primary hydrocarbons, consistent with the additional decrease in oxygenates not observed with aromatics. Because this process affected our sampling inlet, it is possible that oxygenate behavior during early morning is an inlet artifact rather than a significant basin-wide process. We removed rime ice from the sampling inlet early each morn- ing, and other surfaces were typically free of rime by midmorning (snow cover remained during the day).

The values of benzene emission rate derived from the nighttime-only best fit to acetone, acetaldehyde, formic acid, and MEK were slightly higher than estimates from primary compounds: $5 \times 10^{5}$ as opposed to $4 \times 10^{5}$ molecule $\mathrm{cm}^{-3} \mathrm{~s}^{-1}$. This is consistent with an undetermined additional removal process. In the absence of an appropriate loss term, a best fit using Eq. (6) would artificially increase the benzene emission rate to reproduce the stronger downwards trend in ratio.

The diurnal behaviors of methanol and formaldehyde differ significantly from other species. The ratios of methanol and formaldehyde to benzene do not increase steadily during the day and do not decrease at night. Additionally, the values of primary benzene emission rate determined from methanol and formaldehyde are at least a factor of 2 smaller than values determined from any other compound. For methanol, this behavior is almost certainly due to large primary sources. Methanol is used by the oil and natural gas industry in a variety of applications in the basin (Lyman, 2014), including storage of methanol containers on well pads, and direct emissions of methanol associated with this use are very high as witnessed by hourly average mixing ratios in the basin, which can build up to more than 200 ppbv. It is therefore unsurprising that methanol variation is poorly described by Eq. (6). Primary sources of formaldehyde are less clear. Incomplete combustion and emission from dehydrators, separators, compressors, flares, oil pumps and processing plants have been suggested as sources but are not well quantified in the Uintah Basin. Additionally, there is no easily distinguishable correlation between formaldehyde and $\mathrm{NO}_{x}$, so it is not clear that combustion is a significant source of formaldehyde. In accordance with our findings, Edwards et al. (2014) left the option open for primary emissions of formaldehyde due to the inability of the MCM model to reproduce the ambient mixing ratios.

To investigate primary emission of methanol and formaldehyde we modified Eq. (6) in several ways. First, we added a term representing primary emission of oxygenates and determined best-fit values of benzene emission rate and oxygenate : benzene emission ratio. $\chi^{2}$ values decreased insignificantly $(-5 \%)$ for methanol and slightly $(-22 \%)$ for formaldehyde, and calculated values of primary benzene emission rate were unreasonable $\left(8 \times 10^{5}\right.$ and $1 \times 10^{6}$ molecules $\mathrm{cm}^{-3} \mathrm{~s}^{-1}$ from the methanol and formaldehyde analysis, respectively). Next, we fixed the primary benzene emission rate to the value determined from the primary compounds analysis and determined emission ratios for methanol and formaldehyde only. Emission ratios of formaldehyde : benzene and methanol: benzene were 1.01 and 10.3 . These values are slightly less than the ambient ratios, consistent with accumulation from both photochemistry and primary emission. However, the best fit still did not capture the majority of measurement variability and 
may not be accurately characterizing physical processes affecting methanol or formaldehyde. For instance, an emission source poorly correlated with benzene would not be well represented by Eq. (6).

Because of possible complex deposition of oxygenated species during the night, and primary emission of methanol and formaldehyde, emission rates derived from the analysis of these oxygenates are less likely to be accurate than those derived from analysis of primary species. We elected to exclude nighttime data from further analysis, and retain the primary benzene emission rate $\left(P_{\mathrm{B}}\right)$ determined from the primary compounds model. The fit of Eq. (5b) was then calculated for acetone, MEK, acetaldehyde, and formic acid, using daytime data (Fig. 9), to determine values of the formation rate constant $\left(\lambda_{\mathrm{f}}\right)$ for each compound (Table 3 ).

The best-fit of daytime oxygenate ratios is better able to explain the measurements, with $R^{2}$ values of $0.4-0.8$ (Table 3$)$. Values of the formation rate constant $\left(\lambda_{\mathrm{f}}\right)$ are plausible. For instance, the best-fit value of $\lambda_{\mathrm{f}}$ for acetone is $8.72 \times 10^{-11} \mathrm{~cm}^{3}$ molecule $\mathrm{c}^{-1} \mathrm{~s}^{-1}$. The main precursors of acetone present in the Uintah Basin were iso-butane and propane. The weighted average rate constant for reaction of iso-butane and propane with $\mathrm{OH}$ is $1.3 \times 10^{-12} \mathrm{~cm}^{3}$ molecule ${ }^{-1} \mathrm{~s}^{-1}$ and the mole ratio of these compounds to benzene was approximately 70. Assuming that all propane- $\mathrm{OH}$ and iso-butane- $\mathrm{OH}$ reactions formed acetone, the calculated $\lambda_{\mathrm{f}}$ for acetone is $9.1 \times 10^{-11} \mathrm{~cm}^{3}$ molecule ${ }^{-1} \mathrm{~s}^{-1}$, which is very close to the best-fit calculated value. The high $R^{2}$ values and reasonable $\lambda_{\mathrm{f}}$ suggest that Eq. (5b) captures the most important daytime processes affecting acetone, acetaldehyde, MEK, and formic acid.

\section{Organic carbon budget}

In this section, we categorize VOCs as either primary (directly emitted) or secondary (enhanced by oxidative chemistry), and quantify the total organic carbon mass in each category. Using two complementary mass balance approaches, we show that one would expect to see more oxygenated species than were measured. Both approaches rely on conservation of organic carbon mass: when a primary compound is oxidized, the total mass of organic carbon does not change. This is true regardless if the molecule's structure changes, if it fragments into several smaller molecules, if subsequent reactions form higher generation products, or if it moves into a different reservoir (e.g., aerosol or snowpack).

First, carbon mass concentration is conserved. The total organic carbon mass of primary compounds lost to oxidation must be equal to the total organic carbon mass gained by secondary compounds. To quantify this mass, we use the loss rate of a primary compound to oxidation:

$$
\begin{aligned}
& \left.\frac{\mathrm{d}(\text { primary VOC })}{\mathrm{d} t}\right|_{\text {chemical }} \\
& =-k_{\text {primary VOC }}[\mathrm{OH}][\text { primary VOC }] .
\end{aligned}
$$

The amount of organic carbon lost from all primary species measured by PTR-MS and GC-FID (compounds listed in Table 1) during the stagnation event can be found by integrating Eq. (7) for each individual primary VOC, then summing the results over all primary VOCs. For completeness, methane (from CaRDS) was also included. $[\mathrm{OH}]$ was set to the values calculated above (Table 2). $\mathrm{OH}$ rate constants for $\mathrm{C} 8, \mathrm{C}$, and $\mathrm{C} 10$ aromatics were taken from Table 2, and $\mathrm{OH}$ rate constants for all other species were taken from Atkinson and Arey (2003).

Because total carbon mass is conserved, the total carbon mass lost from primary species is equal to the total carbon mass gained by all secondary species. This value, about $3.7 \times 10^{-10} \mathrm{gC} \mathrm{cm}^{-3}$ on day 6 of the stagnation event, is the calculated or expected mass of secondary species. Measured oxygenates and secondary species, including methanol, formaldehyde, formic acid, acetone, acetaldehyde, MEK, PAN species (peroxyacrylic nitric anhydride (APAN), peroxymethacrylic nitric anhydride (MPAN), peroxyacetic nitric anhydride (PAN), and peroxypropionic nitric anhydride (PPN)), organic carbon in snow, and $\mathrm{PM}_{2.5}$ organic aerosol, only sum to $0.64 \times 10^{-10} \mathrm{gC} \mathrm{cm}^{-3}$, or $17 \%$ of calculated secondary carbon mass.

Methanol and formaldehyde have substantial primary sources, so including them in this calculation artificially increases the percentage of secondary species accounted for: $0.64 \times 10^{-10} \mathrm{gC} \mathrm{cm}^{-3}$ is an upper bound to the mass of measured secondary species. If we assume methanol is entirely primary, measured secondary species only sum to $0.48 \times 10^{-10} \mathrm{gC} \mathrm{cm}^{-3}$, or $12.9 \%$ of calculated secondary carbon mass. If we assume both methanol and formaldehyde have no photochemical sources, measured secondary species sum to $0.46 \times 10^{-10} \mathrm{gC} \mathrm{cm}^{-3}$, or $12.5 \%$ of calculated secondary carbon mass. Figure 10 shows the upper bound to measured secondary species (including both methanol and formaldehyde).

This gap between the calculated (expected) mass of secondary species and the measured mass of secondary species is a factor of 5.8 (Fig. 10). Other measurement and modeling studies of the Uintah Basin suggest that unquantified secondary species are responsible for a large part of this gap: many additional oxygenated VOCs were detected, but not quantified, by PTR-time-of-flight (PTR-ToF) mass spectrometry (Warneke et al., 2015), and MCM modeling indicates that carbonyl groups formed from higher-weight species (e.g., aromatics) were not only abundant but major drivers of ozone formation.

Oxidation of quantified secondary species to $\mathrm{CO}$ and $\mathrm{CO}_{2}$, or loss to mixing out of the basin are alternate explanations 


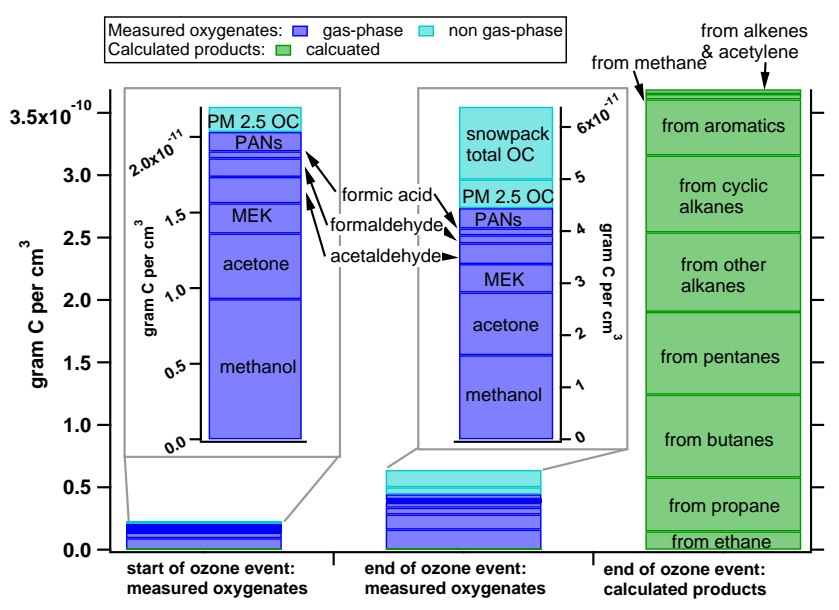

Figure 10. Organic carbon mass of oxygenated and secondary species. The two leftmost bars show the carbon mass of secondary species at the beginning (average of first $12 \mathrm{~h}$ ) and end (average of last $12 \mathrm{~h}$ ) of the ozone event; speciation is detailed in the two insets. Although methanol and formaldehyde may have primary sources, they are included here in the "product compounds" category to show the maximum contribution of these species to measured products. The rightmost bar shows the calculated mass of secondary compounds at the end of the ozone event; within this bar, the contribution from each precursor is delineated.

that could account for some of the disparity. Using a second carbon mass balance technique, we show that unquantified secondary species are an important factor. The second technique compares oxidation rates: the oxidation loss rate of primary species must be equal to the photochemical formation rate of secondary species. Neither of these processes is affected by higher-generation oxidation reactions or loss to mixing or deposition. A disparity between the carbon mass loss rate to oxidation of primary species and the formation rate of measured secondary species means that there must be other, unquantified, secondary species forming. Therefore, comparing oxidation and formation rates provides a way to determine if the mass disparity between calculated and measured secondary species is at least partly due to unquantified compounds.

The total oxidation rate of primary species was determined by applying Eq. (7) to each measured primary species, then summing over all primary species. The formation rate of quantified secondary species was determined using Eq. (4). The first term in Eq. (4), Yield $\cdot k_{\text {precursors }}[\mathrm{OH}]$ [precursors], is the formation rate of a secondary VOC. To clarify, this is the rate at which a secondary VOC is produced by oxidation chemistry, not the rate of net increase in mass (net $=$ formation - loss). As in Eq. (5b), this can be simplified to

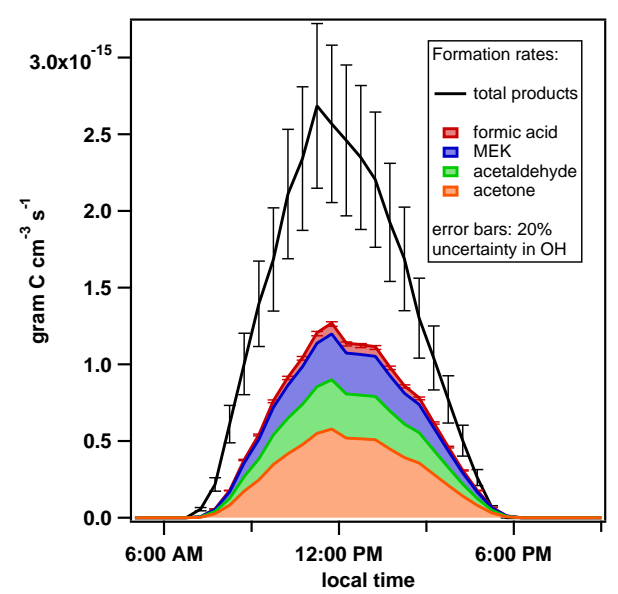

Figure 11. Comparison of total product formation rates (black) and measured carbonyl formation rates. There is a substantial gap that indicates the formation of other oxidation products.

$$
\begin{aligned}
& \left.\left.\frac{\mathrm{d}(\text { secondary VOC })}{\mathrm{d} t}\right|_{\text {formation }}=\lambda_{\mathrm{f}}[\mathrm{OH}] \text { [benzene }\right], \\
& \lambda_{\mathrm{f}}=\text { Yield } \cdot k_{\text {precursors }} \cdot \frac{[\text { precursors }]}{\text { [benzene }]} .
\end{aligned}
$$

$\lambda_{\mathrm{f}}$ is the formation rate constant and was (above) determined for acetone, acetaldehyde, formic acid, and MEK. The oxidation rate of primary compounds is a factor of 2 higher than the formation rate of acetaldehyde, acetone, formic acid, and MEK (Fig. 11). This large disparity indicates a substantial presence of unquantified secondary species. The formation rate of these species is $3.2( \pm 1.2) \times 10^{-16} \mathrm{gC} \mathrm{cm}^{-3} \mathrm{~s}^{-1}$ on average or $60( \pm 23)$ ppbvC day $^{-1}$.

\section{Conclusions}

High concentrations of organic carbon species (up to $5 \mathrm{ppm}$ nonmethane carbon) associated with oil and natural gas extraction were measured at a rural site in the Uintah Basin, Utah, during the winter of 2013. A relatively simple analysis was applied to measurements of aromatic species by PTR-MS to explain variation in their ratios due to reaction with $\mathrm{OH}$ and primary emission. The analysis was extended to measurements of small oxygenated compounds by PTRMS, with the goal of explaining ratios of these compounds to benzene in terms of production and loss via $\mathrm{OH}$ chemistry, photolysis, and primary emission. Results of both analyses were used to develop a carbon mass budget, to determine the relative fractions of carbon in primary and secondary species.

The analysis of primary aromatic species provided plausible estimates of $[\mathrm{OH}]$, aromatic $\mathrm{VOC}$ emission ratios, and benzene emission rate. The daily peak of $[\mathrm{OH}]$ was low $\left(1 \times 10^{6}\right.$ molecule $\left.\mathrm{cm}^{-3}\right)$, consistent with MCM modeling and highlighting the unusual oxidation chemistry 
occurring in this region. Emission ratios indicate source contributions from both oil and gas wells. Using measured correlation between benzene and methane, the benzene emission rate $\left(4.1 \pm 0.4 \times 10^{5}\right.$ molecule $\left.\mathrm{cm}^{-3} \mathrm{~s}^{-1}\right)$ was extrapolated to a basin-wide methane emission rate (27$57 \times 10^{3} \mathrm{~kg}$ methane $\mathrm{h}^{-1}$ ) in order to compare with an independent top-down estimate from aircraft. Although the large uncertainties associated with the extrapolation of the benzene emission rate to a basin-wide methane emission rate preclude the use of our estimate as an assessment of regulatory inventories, the agreement with the 2012 aircraft methane flux value supports the plausibility of our analysis. Our analysis was not able to completely explain nighttime variability of small oxygenated VOCs, whose behavior may be affected by primary emission (methanol and formaldehyde) and deposition to ice surfaces. However, a best fit to daytime data provided values of carbonyl formation rate consistent with expected formation rates from known precursors. The calculated carbon budget indicated that a large fraction of secondary carbon mass $\left(83 \%\right.$, or $\left.3 \times 10^{-10} \mathrm{gC} \mathrm{cm}^{-3}\right)$ is unaccounted for. A comparison of measured carbonyl formation rates to primary compound oxidation rates indicated substantial presence of unquantified secondary species.

The analysis method outlined here is relatively simple, including just a few terms for basic chemistry and primary emission. It uses little computer processing power and references only measurements that can be made with standard VOC instrumentation. Despite its simplicity, this method is able to provide considerable information on VOC chemistry, including source composition and emission rates, the concentration of $\mathrm{OH}$, and measurement thoroughness. Best-fit values are very reasonable and support findings from more complicated chemical models. A similar analysis could be applied to investigations of other regions where VOC pollutants are geographically or meteorologically contained, especially where detailed chemical measurements are unavailable or not possible.

Acknowledgements. The Uintah Basin Winter Ozone Studies were a joint project led and coordinated by the Utah Department of Environmental Quality (UDEQ) and supported by the Uintah Impact Mitigation Special Service District (UIMSSD), the Bureau of Land Management (BLM), the Environmental Protection Agency (EPA), and Utah State University. This work was funded in part by the Western Energy Alliance, and NOAA's Atmospheric Chemistry, Climate, and Carbon Cycle Program. We thank Questar Energy Products for site preparation and support. We thank Colm Sweeney (NOAA GMD) for the use of a Picarro methane instrument, and Shane Murphy and Jeffrey Soltis (University of Wyoming) for the use of a Picarro methane instrument. We thank NOAA Physical Sciences Division for the use of meteorology data, and NOAA Global Monitoring Division for the use of balloon sonde data.

Edited by: J. H. Seinfeld

\section{References}

Adgate, J. L., Goldstein, B. D., and McKenzie, L. M.: Potential public health hazards, exposures and health effects from unconventional natural gas development, Environ. Sci. Technol., 48, 8307-8320, doi:10.1021/es404621d, 2014.

Allen, D. T., Torres, V. M., Thomas, J., Sullivan, D. W., Harrison, M., Hendler, A., Herndon, S. C., Kolb, C. E., Fraser, M. P., Hill, A. D., Lamb, B. K., Miskimins, J., Sawyer, R. F., and Seinfeld, J. H.: Measurements of methane emissions at natural gas production sites in the United States, P. Natl. Acad. Sci. USA, 110, 17768-17773, doi:10.1073/pnas.1304880110, 2013.

Anglada, J. M.: Complex Mechanism of the Gas Phase Reaction between Formic Acid and Hydroxyl Radical. Proton Coupled Electron Transfer versus Radical Hydrogen Abstraction Mechanisms, Am. Chem. Soc., 126, 9809-9820, doi:10.1021/ja0481169, 2004.

Aschmann, S. M., Arey, J., and Atkinson, R.: Rate Constants for the Reactions of OH Radicals with 1,2,4,5-Tetramethylbenzene, Pentamethylbenzene, 2,4,5-Trimethylbenzaldehyde, 2,4,5Trimethylphenol, and 3-Methyl-3-hexene-2,5-dione and Products of $\mathrm{OH}^{+}$1,2,4,5-Tetramethylbenzene, J. Phys. Chem. A, 117, 2556-2568, doi:10.1021/jp400323n, 2013.

Atkinson, R. and Arey, J.: Atmospheric degradation of volatile organic compounds, Chem. Rev., 103, 4605-4638, 2003.

Bates, T. S., Quinn, P. K., Coffman, D. J., Covert, D. S., Miller, T. L., Johnson, J. E., Carmichael, G. R., Uno, I., Guazzotti, S. A., Sodeman, D. A., Prather, K. A., Rivera, M., Russell, L. M., and Merrill, J. T.: Marine boundary layer dust and pollutant transport associated with the passage of a frontal system over eastern Asia, J. Geophys. Res.-Atmos., 109, D19S19, doi:10.1029/2003JD004094, 2004.

Brandt, A. R., Heath, G. A., Kort, E. A., O’Sullivan, F., Pétron, G., Jordaan, S. M., Tans, P., Wilcox, J., Gopstein, A. M., Arent, D., Wofsy, S., Brown, N. J., Bradley, R., Stucky, G. D., Eardley, D., and Harriss, R.: Methane Leaks from North American Natural Gas Systems, Science, 343, 733-735, 2014.

Carter, W. P. L. and Seinfeld, J. H.: Winter ozone formation and VOC incremental reactivities in the Upper Green River Basin of Wyoming, Atmos. Environ., 50, 255-266, doi:10.1016/j.atmosenv.2011.12.025, 2012.

Crosson, E. R.: A cavity ring-down analyzer for measuring atmospheric levels of methane, carbon dioxide, and water vapor, Appl Phys. B, 92, 403-408, doi:10.1007/s00340-008-3135-y, 2008.

de Gouw, J. and Warneke, C.: Measurements of volatile organic compounds in the earth's atmosphere using proton-transferreaction mass spectrometry, Mass. Spectrom. Rev., 26, 223-257, doi:10.1002/mas.20119, 2007.

de Gouw, J. A., Middlebrook, A. M., Warneke, C., Goldan, P. D., Kuster, W. C., Roberts, J. M., Fehsenfeld, F. C., Worsnop, D. R., Canagaratna, M. R., Pszenny, A. A. P., Keene, W. C., Marchewka, M., Bertman, S. B., and Bates, T. S.: Budget of organic carbon in a polluted atmosphere: Results from the New England Air Quality Study in 2002, J. Geophys. Res.-Atmos., 110, D16305, doi:10.1029/2004JD005623, 2005.

Edwards, P. M., Young, C. J., Aikin, K., deGouw, J., Dubé, W. P., Geiger, F., Gilman, J., Helmig, D., Holloway, J. S., Kercher, J., Lerner, B., Martin, R., McLaren, R., Parrish, D. D., Peischl, J., Roberts, J. M., Ryerson, T. B., Thornton, J., Warneke, C., Williams, E. J., and Brown, S. S.: Ozone photochemistry in an 
oil and natural gas extraction region during winter: simulations of a snow-free season in the Uintah Basin, Utah, Atmos. Chem. Phys., 13, 8955-8971, doi:10.5194/acp-13-8955-2013, 2013.

Edwards, P. M., Brown, S. S., Roberts, J. M., Ahmadov, R., Banta, R. M., deGouw, J. A., Dube, W. P., Field, R. A., Flynn, J. H., Gilman, J. B., Graus, M., Helmig, D., Koss, A., Langford, A. O., Lefer, B. L., Lerner, B. M., Li, R., Li, S.-M., McKeen, S. A., Murphy, S. M., Parrish, D. D., Senff, C. J., Soltis, J., Stutz, J., Sweeney, C., Thompson, C. R., Trainer, M. K., Tsai, C., Veres, P. R., Washenfelder, R. A., Warneke, C., Wild, R. J., Young, C. J., Yuan, B., and Zamora, R.: High winter ozone pollution from carbonyl photolysis in an oil and gas basin, Nature, 514, 351354, doi:10.1038/nature13767, 2014.

Etzkorn, T., Klotz, B., Sørensen, S., Barnes, I., Becker, K. H., and Platt, U.: Gas-phase absorption cross sections of 24 monocyclic aromatic hydrocarbons in the UV and IR spectral ranges, Atmos. Environ., 33, 525-540, doi:10.1016/S1352-2310(98)00289-1, 1999.

Gilman, J. B., Burkhart, J. F., Lerner, B. M., Williams, E. J., Kuster, W. C., Goldan, P. D., Murphy, P. C., Warneke, C., Fowler, C., Montzka, S. A., Miller, B. R., Miller, L., Oltmans, S. J., Ryerson, T. B., Cooper, O. R., Stohl, A., and de Gouw, J. A.: Ozone variability and halogen oxidation within the Arctic and sub-Arctic springtime boundary layer, Atmos. Chem. Phys., 10, 10223-10236, doi:10.5194/acp-10-10223-2010, 2010.

Gilman, J. B., Lerner, B. M., Kuster, W. C., and de Gouw, J. A.: Source signature of volatile organic compounds from oil and natural gas operations in northeastern Colorado, Environ. Sci. Technol., 47, 1297-1305, doi:10.1021/es304119a, 2013.

Hard, T. M., Chan, C. Y., Mehrabzadeh, A. A., Pan, W. H., and O'Brien, R. J.: Diurnal cycle of tropospheric OH, Nature, 322, 617-620, 1986.

Jobson, B. T., Niki, H., Yokouchi, Y., Bottenheim, J., Hopper, F., and Leaitch, R.: Measurements of C2-C6 hydrocarbons during the Polar Sunrise 1992 Experiment: Evidence for $\mathrm{Cl}$ atom and $\mathrm{Br}$ atom chemistry, J. Geophys. Res.-Atmos., 99, 25355-25368, doi:10.1029/94JD01243, 1994.

Karion, A., Sweeney, C., Pétron, G., Frost, G., Michael Hardesty, R., Kofler, J., Miller, B. R., Newberger, T., Wolter, S., Banta, R., Brewer, A., Dlugokencky, E., Lang, P., Montzka, S. A., Schnell, R., Tans, P., Trainer, M., Zamora, R., and Conley, S.: Methane emissions estimate from airborne measurements over a western United States natural gas field, Geophys. Res. Lett., 40, 43934397, doi:10.1002/grl.50811, 2013.

Kotamarthi, V. R. and Holdridge, D. J.: Process-scale modeling of elevated wintertime ozone in Wyoming, Argonne National Laboratory, Argonne, IL, 2007.

Kuster, W. C., Jobson, B. T., Karl, T., Riemer, D., Apel, E., Goldan, P. D., and Fehsenfeld, F. C.: Intercomparison of Volatile Organic Carbon Measurement Techniques and Data at La Porte during the TexAQS2000 Air Quality Study, Environ. Sci. Technol., 38, 221-228, doi:10.1021/es034710r, 2004.

Li, R., Warneke, C., Graus, M., Field, R., Geiger, F., Veres, P. R., Soltis, J., Li, S.-M., Murphy, S. M., Sweeney, C., Pétron, G., Roberts, J. M., and de Gouw, J.: Measurements of hydrogen sulfide $\left(\mathrm{H}_{2} \mathrm{~S}\right)$ using PTR-MS: calibration, humidity dependence, inter-comparison and results from field studies in an oil and gas production region, Atmos. Meas. Tech., 7, 3597-3610, doi:10.5194/amt-7-3597-2014, 2014.
Litovitz, A., Curtright, A., Abramzon, S., Burger, N., and Samaras, C.: Estimation of regional air-quality damages from Marcellus Shale natural gas extraction in Pennsylvania, Environ. Res. Lett., 8, 014017, doi:10.1088/1748-9326/8/1/014017, 2013.

Lyman, S.: Formaldehyde and Methanol Emission Sources in the Uinta Basin, Uinta Basin Winter Ozone Study 2014 Post Study Technical Meeting, 16-17 June 2014, Vernal, UT, 2014.

Martinez, R. D., Buitrago, A. A., Howell, N. W., Hearn, C. H., and Joens, J. A.: The near U.V. absorption spectra of several aliphatic aldehydes and ketones at $300 \mathrm{~K}$, Atmos. Environ., 26, 785-792, doi:10.1016/0960-1686(92)90238-G, 1992.

McKeen, S. A., Gierczak, T., Burkholder, J. B., Wennberg, P. O., Hanisco, T. F., Keim, E. R., Gao, R. S., Liu, S. C., Ravishankara, A. R., and Fahey, D. W.: The photochemistry of acetone in the upper troposphere: A source of odd-hydrogen radicals, Geophys. Res. Lett., 24, 3177-3180, doi:10.1029/97g103349, 1997.

Miller, S. M., Wofsy, S. C., Michalak, A. M., Kort, E. A., Andrews, A. E., Biraud, S. C., Dlugokencky, E. J., Eluszkiewicz, J., Fischer, M. L., Janssens-Maenhout, G., Miller, B. R., Miller, J. B., Montzka, S. A., Nehrkorn, T., and Sweeney, C.: Anthropogenic emissions of methane in the United States, P. Natl. Acad. Sci USA, 110, 20018-20022, doi:10.1073/pnas.1314392110, 2013.

Moore, C. W., Zielinska, B., Pétron, G., and Jackson, R. B.: Air Impacts of Increased Natural Gas Acquisition, Processing, and Use: A Critical Review, Environ. Sci. Technol., 48, 8349-8359, doi:10.1021/es4053472, 2014.

Oltmans, S. J., Karion, A., Schnell, R. C., Pétron, G., Sweeney, C., Wolter, S., Neff, D., Montzka, S. A., Miller, B. R., Helmig, D., Johnson, B. J., and Hueber, J.: A high ozone episode in winter 2013 in the Uinta Basin oil and gas region characterized by aircraft measurements, Atmos. Chem. Phys. Discuss., 14, 20117 20157, doi:10.5194/acpd-14-20117-2014, 2014.

Roberts, J. M., Fehsenfeld, F. C., Liu, S. C., Bollinger, M. J., Hahn, C., Albritton, D. L., and Sievers, R. E.: Measurements of aromatic hydrocarbon ratios and $\mathrm{NO}_{x}$ concentrations in the rural troposphere: Observation of air mass photochemical aging and $\mathrm{NO}_{x}$ removal, Atmos. Environ., 18, 2421-2432, doi:10.1016/0004-6981(84)90012-X, 1984.

Rohrer, F. and Berresheim, H.: Strong correlation between levels of tropospheric hydroxyl radicals and solar ultraviolet radiation, Nature, 442, 184-187, doi:10.1038/nature04924, 2006.

Schnell, R. C., Oltmans, S. J., Neely, R. R., Endres, M. S., Molenar, J. V., and White, A. B.: Rapid photochemical production of ozone at high concentrations in a rural site during winter, Nat. Geosci., 2, 120-122, doi:10.1038/ngeo415, 2009.

Shirley, T. R., Brune, W. H., Ren, X., Mao, J., Lesher, R., Cardenas, B., Volkamer, R., Molina, L. T., Molina, M. J., Lamb, B., Velasco, E., Jobson, T., and Alexander, M.: Atmospheric oxidation in the Mexico City Metropolitan Area (MCMA) during April 2003, Atmos. Chem. Phys., 6, 2753-2765, doi:10.5194/acp-62753-2006, 2006.

Slusher, D. L., Huey, L. G., Tanner, D. J., Flocke, F. M., and Roberts, J. M.: A thermal dissociation-chemical ionization mass spectrometry (TD-CIMS) technique for the simultaneous measurement of peroxyacyl nitrates and dinitrogen pentoxide, J. Geophys. Res.-Atmos., 109, D19315, doi:10.1029/2004JD004670, 2004.

US Energy Information Administration: May 2014 Monthly Energy Review, Washington, DC, 2014. 
Utah Oil and Gas: available at: http://oilgas.ogm.utah.gov/Data_ Center/DataCenter.cfm, last access: 3 June 2014.

Warneke, C., Geiger, F., Edwards, P. M., Dube, W., Pétron, G., Kofler, J., Zahn, A., Brown, S. S., Graus, M., Gilman, J. B., Lerner, B. M., Peischl, J., Ryerson, T. B., de Gouw, J. A., and Roberts, J. M.: Volatile organic compound emissions from the oil and natural gas industry in the Uintah Basin, Utah: oil and gas well pad emissions compared to ambient air composition, Atmos. Chem. Phys., 14, 10977-10988, doi:10.5194/acp14-10977-2014, 2014
Warneke, C., Veres, P., Murphy, S. M., Soltis, J., Field, R. A., Graus, M. G., Koss, A., Li, S.-M., Li, R., Yuan, B., Roberts, J. M., and de Gouw, J. A.: PTR-QMS versus PTR-TOF comparison in a region with oil and natural gas extraction industry in the Uintah Basin in 2013, Atmos. Meas. Tech., 8, 411-420, doi:10.5194/amt-8-4112015, 2015. 